\title{
Daño moral colectivo en las relaciones de consumo: caracterización, comparación entre el sistema brasileño y colombiano y la visión del Tribunal Superior de Justicia en Brasil ${ }^{*}$
}

\author{
Recibido: 31 de marzo de 2017 • Aprobado: 17 de junio de 2018 \\ https://doi.org/10.22395/ojum.v18n36a2 \\ Carolina Medeiros Bahia** \\ Heloísa Gomes Medeiros ${ }^{* * *}$
}

\begin{abstract}
RESUMEN
El presente artículo busca discutir el daño moral colectivo en las relaciones de consumo, y se concentra en el concepto actual de daño moral, en el carácter abierto de la categoría de los derechos de la personalidad (que también pasa a abarcar los derechos difusos y colectivos), en la caracterización y las especificidades del daño moral colectivo en el derecho brasileño del consumidor, en la comparación con el sistema colombiano instituido por la Ley 1480 de 2011 y, por fin, en su comprensión en la jurisprudencia reciente del Tribunal Superior de Justicia en Brasil. La metodología utilizada correspondió a la revisión bibliográfica y el examen documental, con las cuales se observaron tanto fuentes legislativas como jurisprudenciales. Se concluyó, primero, que el daño moral colectivo en las relaciones de consumo configura la lesión que afecta al patrimonio moral de la colectividad y acarrea una reducción inmediata de la calidad colectiva de vida; que los sistemas brasileño y colombiano de responsabilidad por productos defectuosos presenta numerosas similitudes; segundo, que a pesar de no haber predicción expresa de la indemnización por daños morales colectivos, están contemplados por la ley colombiana; y se constató la progresiva recepción de la reparación integral del daño moral colectivo en las decisiones recientes del Tribunal Superior de Justicia brasileño, independientemente de la posibilidad de tasación individual de la ofensa, o de la existencia de prueba de que hubo dolor, sentimiento o lesión psíquica para los individuos.

Palabras clave: daño moral colectivo; derecho del consumidor; comparación entre el sistema brasileño y colombiano; visión del Tribunal Superior de Justicia en Brasil.
\end{abstract}

\footnotetext{
El presente artículo es resultado de los procesos de investigación del grupo de investigación Direito Ambiental na Sociedade de Risco (GPDA), perteneciente a la Facultad de Derecho de la Universidad Federal de Santa Catarina.

** Abogada, Universidad Federal de Bahía, Bahía, Brasil, magíster en Derecho, Universidad Federal de Santa Catarina, Santa Catarina, Brasil, doctora en Derecho, Universidad Federal de Santa Catarina, Santa Catarina, Brasil, docente e investigadora, Universidad Federal de Santa Catarina, Santa Catarina. Correo electrónico: carolmbahia@hotmail.com.

*** Abogada, magíster en Derecho, Universidad Federal de Santa Catarina, Santa Catarina, Brasil, doctora en Derecho, Universidad Federal de Santa Catarina, Santa Catarina, Brasil, docente e investigadora, Unidade de Ensino Superior Don Bosco (UNDB). Correo electrónico: medeiroshg@gmail.com.
} 


\title{
The Collective Moral Damage in Consumer Relationships: Characterization, Comparison Between the Brazilian and Colombian Systems and the Vision of the Superior Court of Justice in Brazil
}

\begin{abstract}
This article proposes to discuss the collective moral damage in consumer relations, focusing on the current concept of moral damage; the open character of the category of personal rights, which also cover the diffuse and collective rights; the characterization and the specifics of collective moral damage to consumer law; the comparison with the Colombian system, instituted by Law 1480 of 2011, and finally, their understanding in the recent law of the Supreme Court in Brazil. The methodology used in the investigation was the bibliographic review and the documentary examination, through which legislative and jurisprudential sources were observed. The investigation concluded that the collective moral damage in consumer relations means the injury that affects the moral patrimony of the community, leading to an immediate reduction of collective quality of life; that the Brazilian and Colombian system of liability for defective products have many similarities, and that although the Colombian system does not expressly provide for compensation for collective moral damages, they are covered by Colombian law; and finally, that there was a progressive reception of full compensation for damages collective morals by recent decisions of the Superior Court of Justice, regardless of the possibility of individual measurement of the damage, or of the existence of evidence that there was pain, feeling or psychological damage to individuals. Keywords: collective moral damage; consumer law; comparison between the brazilian and colombian system; the vision of the Superior Court of Justice in Brazil.
\end{abstract}

\section{Dano moral coletivo nas relações de consumo: caracterização, comparação entre os sistemas brasileiro e colombiano e a visão do Tribunal Superior de Justica no Brasil}

\begin{abstract}
RESUMO
O presente artigo busca discutir o dano moral coletivo nas relações de consumo e se concentra no conceito atual de dano moral, no caráter aberto da categoria dos direitos da personalidade (que também passa a abarcar os direitos difusos e coletivos), na caracterização e nas especificidades do dano moral coletivo no direito brasileiro do consumidor, em comparação com o sistema colombiano instituído pela Lei 1480 de 2011 e, por fim, em sua compreensão na jurisprudência recente do Tribunal Superior de Justiça no Brasil. A metodologia utilizada foi a revisão bibliográfica e o exame documental, que incluiu tanto fontes legislativas quanto jurisprudenciais. A pesquisa concluiu que o dano moral coletivo nas relações de consumo configura a lesão que afeta o patrimônio moral da coletividade e acarreta uma redução imediata da qualidade coletiva de vida; que os sistemas brasileiro e colombiano de responsabilidade por produtos defeituosos apresentam numerosas semelhanças e que, apesar de não haver predição expressa pela indenização por danos morais coletivos, eles são contemplados pela lei colombiana e, finalmente, constatou-se a progressiva recepção da reparação integral do dano moral coletivo nas decisões recentes do Tribunal Superior de Justiça brasileiro, independentemente da possibilidade de avaliação individual da ofensa ou da existência da prova de que houve dor, sensação ou lesão psíquica para os indivíduos.

Palavras-chave: dano moral coletivo; direito do consumidor; comparação entre os sistemas brasileiro e colombiano; visão do Tribunal Superior de Justiça no Brasil.
\end{abstract}




\section{INTRODUCCIÓN}

Se verifica, en la actualidad, una verdadera expansión de las áreas de interés protegidas por el orden jurídico como consecuencia de la emergencia de nuevas esferas de proyección de la dignidad humana. Ese fenómeno es particularmente perceptible en el ámbito de los derechos colectivos.

El avance en la protección de los derechos colectivos, difusos e individuales homogéneos y la necesidad de reparar las lesiones que los afectan generó, paulatinamente, el reconocimiento legal, doctrinario y jurisprudencial del denominado daño moral colectivo.

En esta línea se destaca que el Código Brasileño de Defesa del Consumidor es pionero en la materia. En el inicio de la década de 90 delineó un sistema avanzado de responsabilidad civil del proveedor que busca, al tiempo, reparar los daños materiales y morales que afectan al consumidor tanto en su esfera individual como en la colectiva.

Aun así, pasados más de veinticinco años de este desarrollo, y a pesar de los significativos avances en la doctrina y en la jurisprudencia, todavía se constatan diversas dificultades en la caracterización del daño moral colectivo que puede afectar las relaciones de consumo, lo que muchas veces termina por perjudicar la tecnicidad y la previsibilidad de las decisiones que evalúan esas demandas.

Muchos de esos problemas ocurren, por un lado, por la propia falta de consenso doctrinario alrededor de lo que se comprende hoy como daño moral y, por otro lado, de la práctica todavía muy común de realizar, en esta esfera, una mera transposición de la doctrina tradicional del daño moral, sin las necesarias adecuaciones que el carácter transindividual de los intereses difusos y colectivos demanda.

De este modo, son objetivos de este artículo: discutir la conceptuación actual del daño moral, destacar el carácter abierto de la categoría de los derechos de la personalidad -que también abarca los derechos difusos y colectivos- caracterizar el daño moral colectivo en el derecho brasileño del consumidor; presentar una comparación con el sistema colombiano instituido mediante la Ley 1480 de 2011 y, por fin, indagar por la comprensión del daño moral colectivo en la jurisprudencia reciente del Tribunal Superior de Justicia de Brasil.

\section{DAÑO MORAL: UNA CONCEPTUALIZACIÓN DIFÍCIL}

La reparación del daño moral ganó gran importancia con la Constitución Federal de 1988, que previó en los incisos V y X del artículo $5^{\circ}$ la posibilidad de indemnización por el daño exclusivamente moral. 
La reparación de este daño también está expresada en el artículo 186 del Código Civil brasileño que dispone que aquel que, por acción u omisión voluntaria, negligencia o imprudencia, viole el derecho y cause daño a otro, aunque exclusivamente moral, comete acto ilícito.

De la misma manera, no hay ninguna duda respecto a la posibilidad de su reparación y de la acumulación entre el daño patrimonial y el moral oriundos del mismo hecho. Este entendimiento fue expresado desde 1992 por el Tribunal Superior de Justicia (1992, Súmula 37), mientras tanto, superados los debates en torno a su reparación y acumulación, persisten todavía hoy muchas discusiones alrededor de la mejor forma de conceptuar el daño moral.

Sin embargo, la dogmática civil clásica ha acercado el daño moral a una concepción subjetiva, basada en la idea de sufrimiento individual. Se pudo verificar que, en la actualidad, la doctrina y la jurisprudencia tienen alterada esta concepción y han extendido su aplicación a la persona jurídica y a grupos de personas. Prueba de eso es la redacción del artículo 52 del Código Civil de Brasil que determina que "se aplica a las personas jurídicas, en lo que cabe, la protección de los derechos de la personalidad", y la jurisprudencia del Tribunal Superior de Justicia (1999, Súmula 227), que establece que la persona jurídica también puede ser víctima de daño moral.

A pesar de que la mayor parte de las definiciones de daño moral aún recurren a la noción de sufrimiento humano no generado por una pérdida pecuniaria, esa comprensión ha sido blanco de severas críticas por revelarse excesivamente amplia y permitir que casi toda incomodidad o malestar pueda configurar daño moral. En esa línea, Moraes (2006) destaca que la reparación de los daños morales no puede operar más en el nivel del sentido común y que su relevancia actual impone que el concepto alcance un cierto grado de tecnicidad, y que esa falta de rigor científico en la definición del daño moral termina por generar "graves injusticias e incertezas a los involucrados" (p. 244).

Partiendo de una revisión crítica del concepto, que cuestiona la posibilidad de que todo dolor, tristeza o constreñimiento configura daño moral, se verifica, entonces, la emergencia de una nueva concepción, de naturaleza objetiva, que vincula el daño moral a los derechos de la personalidad, considerándolo como una lesión a esos derechos o a la propia dignidad de la persona humana (Moraes, 2006).

En este contexto, el presupuesto del daño pasa a situarse en la propia actividad lesiva (daño normativo), y no importan, para su configuración, las alteraciones que eventualmente promueva en el estado anímico de la víctima. Dolor, sufrimiento, humillación 
y angustia se tornan así, apenas consecuencias posibles del daño moral, que deben ser consideradas en el momento de su cuantificación, y no el daño moral en sí.

Se puede decir, entonces, que el daño moral no está obligatoriamente atado a alguna reacción psíquica de la víctima, de modo que, como bien percibe Cavalieri Filho (2012), "puede haber ofensa a la dignidad de la persona humana sin dolor, vejación o sufrimiento, así como puede haber dolor, vejación y sufrimiento sin violación de la dignidad" (p. 89).

Como consecuencia de esa objetivación progresiva del daño moral, la jurisprudencia reciente, sobre todo del Tribunal Superior de Justicia, viene dispensando la prueba del daño moral cuando este resulta de la violación de derechos de la personalidad. Aquí se comprende que la gravedad del comportamiento del agente, aliada a la constatación de la ofensa al bien jurídico tutelado, es suficiente para inferir la ocurrencia de daño, cuidándose entonces de la hipótesis de daño moral presumido o in re ipsa.

La reparación del daño moral se facilita más, pues pasa a depender solamente de la prueba del hecho que lo haya causado. Así, una vez demostrado el hecho de la violación al derecho de la personalidad, el daño moral pasa a ser encarado como hecho notorio (artículo 374, I del Código de Procedimiento Civil-CPC) o como hecho presumido por el juez por fuerza de la aplicación de las reglas de experiencia (artículo 375 del CPC) (Amaro, 2009).

Si se comprende el daño moral como ofensa al derecho de la personalidad o como lesión a la dignidad humana, es el momento de considerar la posibilidad que tiene esta categoría de derechos para abarcar derechos difusos y colectivos también. Es lo que será abordado en el siguiente tema.

\section{DERECHOS DE LA PERSONALIDAD COMO CATEGORÍA "ABIERTA", QUE TAMBIÉN CONTEMPLA LOS DERECHOS DIFUSOS Y COLECTIVOS}

Los derechos de la personalidad ya fueron definidos como "los derechos propios del ser humano" (Borges, 2009, p. 25) o como "el conjunto de atributos inherentes a la condición humana" (Farias y Rosenvald, 2016, p. 214). Como bien observa Borges (2009, p. 25), ellos no constituyen verdaderamente un derecho de la personalidad, una vez que ellos no tienen la personalidad como objeto, cuidan, antes, de derechos decurrentes de la personalidad, que derivan de algunas de sus cualidades, expresiones o proyecciones. Se tratan, así, de derechos enfocados a la concreción de la cláusula general de protección de la persona humana contenida en el inciso III del artículo $1^{\circ}$ de la Constitución Federal. 
Además de absolutos, imprescriptibles, vitalicios, y de ser marcados por una indisponibilidad relativa, los derechos de la personalidad también presentan un carácter necesariamente abierto: jamás pueden configurar numerus clausus, pues a medida que las relaciones sociales se tornan más complejas, emergen nuevas formas de violación a la persona, las cuales pasan a demandar una respuesta jurídica. Por eso, las listas de derechos de la personalidad presentes tanto en la Constitución Federal como en el Código Civil de 2002 tienen un carácter meramente ejemplificativo, tales listas no impiden la identificación y protección de otros derechos que, aunque no estén previstos de manera expresa, se orientan hacia la protección de la dignidad de la persona humana.

Los derechos de la personalidad, en esta línea de raciocinio, pueden ser reputados como derechos en expansión que siempre se amplían con "la evolución legislativa y el desarrollo del conocimiento científico acerca del derecho" (Borges, 2009, p. 25), impidiendo con esto que nuevos y eventuales valores incorporados a la personalidad queden sin la debida tutela jurídica.

Ese carácter expansivo de los derechos de la personalidad queda muy evidenciado, actualmente, en relación a las dimensiones difusa y colectiva de la personalidad, que ha ganado relevancia, sobre todo con el surgimiento y la consolidación de la "sociedad de masas" que, privilegiando en marcha el progreso de la técnica y la exacerbación de la producción industrial, expone la colectividad a una serie de nuevas amenazas de difícil control y gestión por las instancias administrativas. Tómense como ejemplos las lesiones ambientales que terminan por privar la colectividad del acceso al medio ambiente equilibrado, o las posibles violaciones ocasionadas por una publicidad engañosa o abusiva.

En esa línea de pensamiento, repensar la categoría de los derechos de la personalidad a la luz de las nuevas exigencias sociales de modo a englobar, al lado de los derechos individuales, los derechos de personas vulnerables, como los consumidores, los ancianos, los niños y los adolescentes, los indígenas y los afectados por la nocividad ambiental, es una tarea urgente para los operadores del derecho.

Esa función viene siendo asimilada por los tribunales, como bien ejemplifica el brillante pasaje del voto de la ministra Eliana Calmon, en apreciación del Recurso Especial 1057274/RS (Tribunal Superior de Justicia, 2009) que reconoció que el daño moral extrapatrimonial alcanza derechos de personalidad del grupo o colectividad como realidad masificada, que cada día reclama más soluciones jurídicas para su protección. Por eso, entendió que era evidente que una colectividad de indígenas puede sufrir ofensa al honor, a su dignidad, a su buena reputación, a su historia, a sus costumbres y tradiciones y que eso no implica exigir que la colectividad sienta el 
dolor, la repulsión, la indignación tal cual fuera un individuo aislado. Estas derivan del sentimiento colectivo de participar de determinado grupo, de esta forma se relaciona la propia individualidad a la idea del colectivo.

En esta decisión, el reconocimiento de la existencia del daño moral colectivo solo fue posible a partir de la comprensión de los derechos de la personalidad como categoría abierta que también abarca, entre otros, el derecho al medio ambiente ecológicamente equilibrado y el derecho de los pueblos indígenas, estos también indispensables para la concretización de una vida saludable y con dignidad. Se trata también de reconocer que el legislador brasileño, al lado de los derechos estrictamente individuales, también confirió a la colectividad derechos informados por valores extrapatrimoniales, de naturaleza transindividual, que dejan de tener al individuo, aisladamente considerado, como referencia.

A partir de esas bases, se observa una consecuente ampliación en la propia comprensión del daño moral que, como será profundizado a continuación, deja de limitarse a la alteración de un estado anímico, inherente a las personas naturales, para también alcanzar el deber de reparar daños extrapatrimoniales de naturaleza difusa y colectiva (Mello, 2014, p. 60).

\section{LA CARACTERIZACIÓN DEL DAÑO MORAL COLECTIVO EN EL DERECHO DEL CONSUMIDOR BRASILEÑO}

El daño moral colectivo y su creciente reconocimiento por la doctrina y la jurisprudencia brasileña deben ser contextualizados en el marco del paradigma de la sociedad de riesgo, estructurado por el sociólogo alemán Ulrich Beck (2002), quien percibe la emergencia, a partir de mediados del siglo XX, de una serie de nuevos desafíos tecnológicos, como la energía nuclear, diversos tipos de producción química y biotecnológica y la persistente amenaza de destrucción ecológica, que subvierten las bases de la lógica de riesgos entonces reinante y que, partiendo de decisiones humanas, presentan la posibilidad de destrucción de toda la vida del planeta.

Es, precisamente, la naturaleza de los nuevos riesgos que diferencia la época actual de la primera fase de la Revolución Industrial y de todas las formas sociales ya existentes, conformando lo que el autor denomina sociedad del riesgo. La sociedad del riesgo sería "un estadio de la modernidad en que empiezan a tomar cuerpo las amenazas producidas hasta entonces en el camino de la sociedad industrial" (Beck, 1997, p. 17), es un producto del intenso crecimiento económico, del acelerado progreso de la técnica y de la radicalización del proceso industrial, o sea, del propio éxito de la modernización. 
Además de la globalidad, de la proyección en el tiempo y de las dificultades de control, otra característica de los nuevos riesgos se destaca en la obra de Beck: su invisibilidad hacia los sentidos humanos. Resalta el autor que:

La vida cotidiana es ciega respecto a los peligros que amenazan la vida y, por lo tanto, depende, en sus decisiones, de expertos y contraexpertos. No se trata únicamente del daño potencial, sino también que esta 'expropiación de sentidos' por los riesgos globales hace insegura la vida (Beck, 2002, p. 86).

En este escenario, los estados de incertidumbre frecuentemente se manifiestan sin que los afectados tengan conciencia de su origen, desarrollo o incluso de su propia manifestación. En algunos casos, no se activan ni siquiera durante la vida de los afectados, sino en la de sus descendientes y necesitan los órganos perceptivos de la ciencia para que sean visibles e interpretables como peligros (Beck, 1998, p. 33).

La Ley 8078 de 1990, que establece el código brasileño de defesa del consumidor, en sintonía con el nuevo paradigma, consagra, en su artículo $6^{\circ}$, VI, la efectiva prevención y reparación de daños patrimoniales y morales, individuales, colectivos o difusos como un derecho básico del consumidor, acogiendo así el principio de la reparación integral y dejando claro que en el ámbito de las relaciones de consumo la reparación de los daños morales alcanza tanto las lesiones individuales como las de naturaleza colectiva.

En su dimensión individual, el daño moral al consumidor configura una violación a derechos personalísimos pertenecientes al consumidor y, en razón de su carácter individual, en principio apenas su titular puede requerir su reparación, valiéndose por tanto de las reglas procesales tradicionales, por lo cual los valores obtenidos a título de indemnización deben ser a destinados él de forma directa. Excepcionalmente, si está caracterizada la presencia de intereses individuales homogéneos, será posible el recurso a la acción colectiva.

La acción del daño moral individual sigue la regla general del código de defensa del consumidor y, por eso, salvo las hipótesis de prestación personal de servicio por profesional liberal (artículo 14, §4 del CDC), se basará en la naturaleza objetiva de la responsabilidad civil.

Respecto a la fijación de la indemnización, no existen actualmente parámetros legales para la fijación del valor a ser pagado a la víctima, el Código Civil se limita a establecer, en su artículo 944, que la indemnización debe medirse por la extensión del daño. 
De acuerdo con Amaro, la cuantificación del daño moral individual debe llevar en consideración la extensión del daño, confrontándola con la capacidad económica del lesionado y observando, todavía, la repercusión del daño bajo el prisma interno y externo (2009, p. 167). Debe la indemnización, en este cuadro, servir tanto como lenitivo, para eliminar y disminuir el dolor y el malestar sufridos por la víctima, y como medio de inhibir al ofensor, para que este no vuelva a causar lesión extrapatrimonial.

Obsérvese que admitir un efecto disuasivo para la indemnización debido al daño moral no significa necesariamente defender la aplicación de los punitive damages en este campo. A pesar de su creciente aceptación, la tesis del daño moral punitivo encuentra todavía fuertes resistencias doctrinarias, cuya discusión más profunda no sería posible en el corto espacio de este artículo.

Ya en su acepción colectiva, el daño moral se traduce en una lesión en la esfera social de un grupo (determinable o no) de sujetos, que no se confunde con el patrimonio material o moral de los individuos que lo componen. Se trata de la ofensa a intereses no patrimoniales colectivos que presentan una base fáctica común, aunque no exista una previa relación jurídica entre sus miembros y acarrea un rebajamiento inmediato de la calidad colectiva de vida.

Como observa Mello (2014, p. 60), ese daño alcanza el patrimonio moral transindividual, perteneciente a la colectividad que "aunque considerada como ente despersonalizado, titulariza valores morales y presenta un patrimonio ideal, que demanda protección". En ese sentido, el reconocimiento legal de la colectividad como titular de bienes inmateriales jurídicamente relevantes debe corresponder a la existencia de mecanismos adecuados para la prevención y la reparación de las lesiones que los afecten, justificando, así, la reparación de los daños morales colectivos.

Según Steigleder (2004, p. 164), el fundamento para su admisibilidad es la existencia de valores que nortean la colectividad, concebida como un conglomerado de personas que viven en determinado territorio y se encuentran unidas por factores comunes. Esos valores portan referencia a la comunidad, independientemente de sus miembros y, por esto, presentan naturaleza autónoma e indivisible.

Ahora bien, el daño extrapatrimonial colectivo no siempre fue interpretado de esa forma. En una primera aproximación, este daño fue comprendido por la doctrina brasileña como una lesión capaz de causar dolor, sufrimiento o aflicción a una colectividad o grupo de personas. En esa dirección iba la definición de Mirra (2010, p. 438), para quien el daño moral colectivo consistiría en el dolor o en el sentimiento de frustración de la sociedad. 
Para Paccagnella (2010, p. 594), el objetivo de la responsabilidad por el daño moral colectivo era el mismo del daño moral individual, o sea, reparar el sufrimiento, el dolor, el disgusto del ser humano. La única diferencia era que el daño extrapatrimonial colectivo se refería al sufrimiento de diversas personas dispersas en cierta colectividad o grupo social (dolor difuso o colectivo). Esa definición ofrece problemas, pues, además de que la ofensa a la integridad psicofísica de la colectividad es de cuestionable existencia (Barbosa y Multedo, 2014, p. 42), ella no se concilia con la visión civil y constitucional en torno del tema.

Es apenas a partir de una perspectiva objetiva de daño moral, que comprende como lesión determinada categoría de derechos y del acogimiento de una concepción abierta de derechos de la personalidad, que admite su extensión para alcanzar los nuevos derechos, es posible avanzar hacia la caracterización del daño moral colectivo en las relaciones de consumo.

En ese sentido, los derechos de los consumidores deben ser comprendidos como derechos de la personalidad, autónomos en relación a los derechos patrimoniales, pues la protección de esta categoría de sujetos, vulnerables en el mercado de consumo, representa una condición indispensable para el pleno desarrollo de la personalidad humana.

De esta manera, a través de una visión renovada de este instituto, el daño extrapatrimonial al consumidor dispensa la existencia de dolor como elemento esencial, bastando, para su configuración, la ocurrencia de ofensa a valores colectivos, comprendidos como el conjunto de creencias, costumbres y significados, que componen el patrimonio moral de la colectividad.

Santana (2014, p. 148) destaca que el daño moral colectivo en las relaciones de consumo puede configurarse en frecuentes situaciones como en la publicidad discriminatoria de parte de consumidores, en la venta o exposición de productos inseguros, en la privación de servicio público esencial o en el incumplimiento generalizado del contrato de consumo.

Los hechos recientes de la historia brasileña también ejemplifican el daño moral colectivo. En el caso de "la huelga de los camioneros", movimiento ocurrido entre mayo y junio del 2018, cuando camioneros autónomos paralizaron sus actividades, bloqueando carreteras en todo Brasil como forma de protesta contra los reajustes frecuentes y sin previsibilidad mínima en los precios de los combustibles, principalmente del diésel, ajustes realizados casi a diario por la estatal Petrobras, además, reclamaban el fin del cobro de peaje por eje suspendido y la supresión de algunos tributos sobre el diésel. 
La paralización y los bloqueos de carreteras en 24 estados y en el Distrito Federal acarrearon diversos daños morales colectivos, como la escasez de alimentos y medicamentos por todo el territorio nacional, la escasez y el alza de precios de los combustibles, con largas filas para abastecer. Además, varias actividades económicas fueron suspendidas, muchos vuelos fueron cancelados, las flotas de autobuses fueron reducidas en diversas ciudades y una cantidad inmensa de aves y cerdos murieron por falta de ración.

Aunque su aceptabilidad sea creciente, aún existen en la doctrina autores contrarios a la reparación del daño moral colectivo. Las principales objeciones a su reconocimiento se fundan en el requisito de la personalidad del daño, en la ausencia del sujeto individual lesionado, en la dificultad de identificar los lesionado para probar, cuantificar y reclamar judicialmente la reparación (Galdós, 2009, p. 289). Es cierto, sin embargo, que si existen problemas alrededor del tema, su solución no pasa por la mera negación de su existencia, cabiendo así a los juristas la tarea de adaptar los mecanismos de la responsabilidad civil a las peculiaridades del daño moral colectivo como forma de garantizar el acatamiento a los dictámenes del principio de la reparación integral. Además, en este escenario, parecería contradictorio que se admita la reparación del daño moral que afecta a las personas jurídicas y negar la reparación del daño que alcanza los valores inmateriales que rigen la colectividad.

Se debe, entonces, avanzar y admitir, por ejemplo, que el requisito de la personalidad no tiene aplicabilidad en el ámbito del daño moral colectivo, delante de la frecuente imposibilidad de identificar con precisión las víctimas del evento y de evaluar individualmente la lesión. Con todo, tal como ocurre con los daños en general, no es cualquier perturbación que puede configurar daño extrapatrimonial colectivo. En este sentido la jurisprudencia del Tribunal Superior de Justicia ha establecido que apenas cuando el hecho transgresor sea relevante, sobrepasando los límites de tolerabilidad, habrá daño moral colectivo reparable.

Distintamente del daño moral individual, aquí el agravio es colectivo y no se traduce personalmente a sus miembros. Por cuenta de esto, su tutela procesal debe ser hecha por medio de instrumentos procesales adecuados, de índole colectiva, y una eventual indemnización debe ser destinada al Fondo de Reparación de los Bienes Lesionados, previsto en el artículo 13 de la Ley de la acción civil pública, volviéndose hacia la propia colectividad.

Desde el punto de vista probatorio, por ser menos evidente, el daño moral colectivo tiene una prueba todavía más difícil, debiendo por eso, en la misma línea del daño moral individual, ser presumido en virtud de la gravedad de la lesión. 


\section{COMPARACIÓN CON EL SISTEMA COLOMBIANO INSTITUIDO POR LA LEY I480 DE 2011}

En el diseño del sistema brasileño de responsabilidad civil por accidentes de consumo, además de unificar las esferas contractual y extracontractual, el Código Brasileño de Defensa del Consumidor introdujo un fundamento objetivo para el deber de indemnizar, pautado en la dispensa de comprobación de la culpa del agente causante del agente daños, de conformidad con los artículos 12 y 14 de la Ley 8078 de 1990. Con ello, erigió como requisitos para la responsabilidad civil frente al consumidor: la demostración de la existencia de defecto del producto o del servicio, de daño y de nexo de causalidad.

Por opción legislativa, se adoptó la presunción juris tantum de la existencia del defecto del producto o del servicio, imponiéndose al consumidor la carga de probar solo el daño y el nexo de causalidad.

En virtud de la imposibilidad de garantizar, en el ámbito de la seguridad del consumidor, la eliminación de toda forma de peligro, en principio, solo un producto o servicio considerado defectuoso da lugar al deber de reparar. Teniendo como criterio la seguridad de los productos, la doctrina suele clasificar la peligrosidad que ellos pueden presentar en inherente o adquirida. En el primer caso, la peligrosidad es indispensable para la propia utilidad del producto, deriva de su propia naturaleza o forma de utilización y es compatible con las expectativas legítimas del consumidor. Es lo que ocurre con los cuchillos, que tienen aptitud para causar lesiones físicas, las almohadas y bolsas plásticas, que pueden causar sofocación, etc. En estos casos, como el peligro intrínseco al producto es ampliamente conocido por la colectividad (que puede prevenirse, adoptando los cuidados necesarios), los daños causados por ellos no dan el deber de reparar.

La peligrosidad, a su vez, se adquiere cuando no presenta una correspondencia con esas mismas expectativas legítimas y, por lo tanto, resulta imprevisible, sorprendente para el consumidor. De este modo, por regla general, se considera defectuoso, un producto o servicio, cuando tenga una peligrosidad adquirida. En otras palabras, para ser defectuoso, el producto o servicio debe, a la vez, presentar aptitud para provocar accidentes y contrarrestar las expectativas legítimas generadas en torno a su seguridad.

En cuanto a estas expectativas, Benjamin, Marques y Bessa (2007) aclara que no se trata de una mera expectativa individual, sino media del público objetivo y que la simple colocación de un producto con calidad superior en el mercado no hace de los productos de calidad inferior necesariamente defectuosos. 
El daño, como requisito para la imposición de la responsabilidad civil, debe abarcar, en los términos del artículo 6, VI del Código Brasileño de Defensa del Consumidor, todos los perjuicios soportados por los consumidores, sean de orden moral, patrimonial, individual, colectivo o difuso. Con ello, se verifica la clara opción del legislador brasileño por el principio de la reparación integral, que además de ampliar el círculo de los daños reembolsables intenta asegurar la reparación de las víctimas de los accidentes de consumo, tanto en la perspectiva individual como en la colectiva y difusa.

El nexo causal puede ser comprendido como el eslabón establecido entre una conducta antecedente y un resultado dañino. El vínculo une el daño directamente al hecho e indirectamente al elemento de atribución objetiva de la responsabilidad (Alsina, 1997, p. 267). De innegable importancia, este elemento presenta una doble función en el campo de la responsabilidad civil, pues, al mismo tiempo que permite, con rigor científico, la identificación del agente responsable de la producción del resultado, presenta criterios objetivos para la medición del tamaño del daño que se reparará (Mulholland, 2009).

En el ámbito de las relaciones de consumo, se optó por la teoría del riesgo de la actividad, con la previsión expresa de tres excluyentes de responsabilidad: la no introducción del producto en el mercado, la ausencia de defecto y el hecho exclusivo del consumidor o de tercero. El caso fortuito y la fuerza mayor, aunque no previstos en el texto legal, también integran el rol de los excluyentes de la responsabilidad del proveedor, en virtud de romper el nexo de causalidad que vincula la actividad del agente al daño.

De modo similar al sistema brasileño, la Ley 1480 de 2011, al desarrollar el mandato contenido en el artículo 78 de la Constitución Política de Colombia, acoge, como fundamento para la responsabilidad por productos o servicios defectuosos, la existencia de un deber general de seguridad de los productores y proveedores en el mercado. De este modo, el artículo 1.1 de la Ley 1480 de 2011 establece, como principio general, la protección de los consumidores contra los riesgos para su salud y seguridad. El artículo 3.1.2, a su vez, reconoce como derecho de los consumidores que los productos no causan daños en condiciones normales de uso y la protección contra consecuencias perjudiciales para la salud, vida o integridad de los consumidores.

El artículo 6 reitera el deber de seguridad, determinando que el incumplimiento de este deber acarreará la responsabilidad administrativa y por daños derivados de un producto defectuoso, conforme a los artículos 19 y siguientes de la ley. Según el artículo 20 del Estatuto de Protección del Consumidor, la responsabilidad por productos defectuosos se aplica cuando un consumidor o usuario sufre muerte, lesión 
corporal o daño a bienes diversos del producto defectuoso, como consecuencia de un error de fabricación, diseño o información de un producto o servicio.

En este punto, como destaca Apráez (2015, p. 389), se puede observar no solo la irrelevancia del vínculo contractual para estructurar esta modalidad de responsabilidad como su no sumisión a la lógica del principio de la relatividad de los efectos de los contratos. A pesar de que no hace referencia expresa a los daños morales colectivos, se puede comprender que ellos configuran daños externos al producto o servicio defectuoso, insertándose en este dispositivo. Para la ley (artículo 5.8), el concepto de producto es más amplio, no habiendo distinción entre bienes muebles e inmuebles, corporales e incorporales, incluidos los servicios.

El artículo 5.17 considera como producto defectuoso el bien mueble o inmueble que, debido a un error de diseño, fabricación, construcción, embalaje o información, no ofrece la seguridad razonable a la que toda persona tiene derecho. Cuéllar (2014, p. 23) critica la definición colombiana por centrarse en la idea de error y no en la de defecto, que se vincula a la noción de seguridad legítimamente esperada o razonable y es seguida por la mayor parte de los ordenamientos jurídicos, incluso el brasileño.

Para Apráez (2015, p. 393), se considera que a pesar de que se haya incluido la palabra 'error' dentro de la definición de productos defectuosos "no se desvirtúa el carácter objetivo de la responsabilidad en cuestión, y que se trata quizá de un problema de técnica legislativa, que no puede traducirse en el establecimiento de una exigencia adicional para el afectado". Además, la prueba de que el empresario cometió un error en el diseño, fabricación, construcción, embalaje o suministro de la información de un producto que hace que este sea defectuoso resulta prácticamente imposible para el afectado.

En esta línea, la Corte Constitucional y la Corte Suprema de Justicia colombianas, en decisiones anteriores a la nueva ley, admitieron que "para comprobar el defecto, el consumidor debe probar solamente que el producto no brindaba la seguridad a que una persona tiene legítimamente derecho" (como se cita en Cuéllar, 2014, p. 23).

Por último, el sistema colombiano de responsabilidad por producto defectuoso sigue, de la misma forma que el sistema brasileño, la responsabilidad objetiva o sin culpa. Esta conclusión resulta del análisis de las causas de exoneración que pueden ser alegadas por los productores y proveedores para deshacerse de la responsabilidad. Conforme al artículo 22, el demandado solo puede alegar la presencia de las causas extrañas, siendo irrelevante la demostración de que actuó diligentemente. Es de destacar que, a diferencia del Código de Defensa del Consumidor brasileño, el Estatuto de Protección al Consumidor de Colombia considera que la presencia de riesgos de 
desarrollo configura una causa extraña no imputable, que exonera de responsabilidad a los productores o proveedores.

\section{EL DAÑO MORAL COLECTIVO EN LAS RELACIONES DE CONSUMO SEGÚN LA JURISPRUDENCIA DEL TRIBUNAL SUPERIOR DE JUSTICIA EN BRASIL}

El daño moral colectivo recorrió un largo camino hasta tener su reparación reconocida por los tribunales. El Tribunal Superior de Justicia analizó la juridicidad del daño moral colectivo por primera vez apenas en 2006, por medio del Recurso Especial 598281/MG (Tribunal Superior de Justicia, 2006), redactado por el ministro Luiz Fux.

Se trataba de un recurso extraordinario contra juicio del Tribunal de Justicia de Minas Gerais, que falló por la imposibilidad de condenación de daño moral colectivo en sede de acción civil pública en la cual se discute la reparación de daños al medio ambiente. Aunque el voto del relator haya sido favorable a reconocimiento del daño ambiental moral colectivo, el primer grupo terminó perfilando el entendimiento del ministro Teori Zavascki para quien, a pesar de que el daño ambiental o ecológico puede, en tesis, acarrear también el daño moral, la víctima del daño moral debe ser necesariamente una persona, pues este daño no sería compatible con la transindividualidad de la lesión.

El equívoco de esta decisión está en el no reconocimiento de que, al lado de las lesiones individuales, en el daño moral colectivo existe la ofensa a valores relevantes para la sociedad que, en razón su carácter común, no son usufructuados de manera individual o exclusiva. En esas lesiones, la víctima directa es la colectividad y no los individuos aisladamente considerados, aun cuando las consecuencias de estos daños repercutan sobre ellos (Galdós, 2009, p. 289).

Tres años más tarde, el segundo grupo tuvo oportunidad de apreciar la cuestión, por medio del Recurso Especial 1057274/RS, de redacción de la ministra Eliana Cal mon. La decisión debatió la posibilidad de configuración de daño moral colectivo perpetrado por una empresa de transporte que exigía procedimiento de registro de ancianos para que estos pudieran disponer del beneficio del pase libre.

Este juzgado, de manera más avanzada, afirmó el carácter transindividual del daño moral colectivo y su aptitud para alcanzar una clase específica o no de personas, comprendiendo que su comprobación se da por la presencia de prejuicio a la imagen y a la moral colectiva de los individuos como síntesis de las individualidades percibidas como segmento, derivado de una misma relación jurídica-base. Reconoció que, en su 
dimensión colectiva, el daño moral dispensa la comprobación de dolor, de sufrimiento y de afectación psicológica, inaplicable a los intereses difusos y colectivos.

A partir de estos presupuestos, entendió que la sumisión de los ancianos al procedimiento de registro para el disfrute del beneficio del pase libre, con el desplazamiento costeado por los interesados, violaba el artículo 39, $\S 1^{\circ}$ del Estatuto del Anciano, configurando daño moral colectivo resarcible.

Al apreciar el Recurso Especial 1.221.756-RJ (Tribunal Superior de Justicia), en febrero de 2012, el tercer grupo condenó una institución bancaria al pago de cincuenta mil reales a título de daños morales colectivos, en razón de imponer a los consumidores con dificultades de locomoción la exigencia de subir tramos de escaleras para obtener atención, comprendiendo que no es razonable someter aquellos que ya poseen dificultades de locomoción, sea por la edad, sea por deficiencia física, o por causa transitoria, a la situación desgastante de subir tramos de escaleras, exactas 23 gradas, en agencia bancaria que posee plena capacidad y condiciones de propiciar mejor forma de atención a tales consumidores.

Más recientemente, el Tribunal Superior de Justicia reconoció, en el Recurso Especial 1.397.870-MG (Tribunal Superior de Justicia, 2018), la presencia de daño moral colectivo decurrente de la práctica de venta casada por una operadora de telefonía que ofrecía a los consumidores líneas telefónicas con valores más atractivos que los de la competencia, condicionando esel beneficio a la adquisición de un aparato telefónico comercializado por ella. El juzgado defiende que la práctica de venta casada por parte de operadora de telefonía es capaz de romper con los límites de la tolerancia y que en el momento en que ofrece al consumidor un producto con significativas ventajas -en el caso, el comercio de línea telefónica con valores más interesantes de lo que la de sus competidores- pero paralelamente, le impone la obligación de adquisición de un aparato telefónico por ella comercializado, realiza una práctica comercial apta para causar sensación de repulsa colectiva a un acto intolerable, tan intolerable que encuentra prohibición expresa en la ley. La decisión consideró que alejar la incidencia de daño moral difuso, en la hipótesis, sería lo mismo que hacer tabla rasa de la prohibición establecida en el artículo 39, I, del CDC legitimando prácticas comerciales que violan los más básicos derechos del consumidor.

Se puede verificar, a partir del análisis de estas sentencias, que los tribunales nacionales vienen madurando la idea del daño moral colectivo en las relaciones de consumo, apuntando para la tendencia doctrinaria que admite su reparación integral, independientemente de la posibilidad de mensuración individual de la ofensa a intereses difusos o colectivos de la comunidad, o de la existencia de prueba de que hubo dolor, sufrimiento o lesión psíquica para los individuos. 


\section{CONCLUSIONES}

El Código Brasileño de Defensa del Consumidor estructuró un sistema avanzado de responsabilidad civil y asegura la reparación tanto de los daños materiales como morales, sea en su dimensión individual o colectiva.

A despecho de los significativos avances doctrinarios y jurisprudenciales, persisten dificultades en la caracterización del daño moral colectivo que puede presentarse en las relaciones de consumo, sobre todo por cuenta de la falta de consenso en torno del concepto de daño moral y en razón de la tentativa de realizar, en esta esfera, una mera transposición de la doctrina tradicional del daño moral, sin las necesarias adaptaciones.

Sobre el concepto de daño moral, se constató la tendencia actual de definirlo de una manera más objetiva, como ofensa al derecho de la personalidad o como lesión a la dignidad humana.

Respecto de los derechos de la personalidad, se verificó que ellos constituyen una categoría abierta, sometida a constantes adaptaciones por fuerza de los cambios sociales, y que engloban, hoy día, al lado de los derechos individuales, también los derechos difusos y colectivos.

Como consecuencia de estos factores, se verifica una ampliación en la propia comprensión del daño moral, que deja de limitarse a la alteración de un estado anímico, inherente a las personas naturales, para también alcanzar el deber de reparar daños extrapatrimoniales de naturaleza difusa y colectiva.

Así, el daño moral colectivo en las relaciones de consumo fue caracterizado como la lesión que afecta el patrimonio moral de la colectividad, acarreando un rebajamiento inmediato de la calidad colectiva de vida, independientemente de la existencia de dolor como elemento esencial.

El carácter colectivo de ese daño pasa a exigir, con todo, una revisión de los dogmas clásicos de la responsabilidad civil, la cual debe adaptarse a sus peculiaridades.

A partir de una comparación entre el sistema brasileño y el sistema colombiano de responsabilidad por productos defectuosos, se observó que ellos presentan muchas similitudes y que, a pesar de no haber predicción expresa de la indemnización por daños morales colectivos, estos daños se encuadran en la previsión del artículo 20 de la Ley colombiana 1480 de 2011. 
Por fin, se realizó un estudio de las recientes decisiones del Tribunal Superior de Justicia de Brasil, constatándose la progresiva recepción a esas ideas y la tendencia a generar un panorama que admite a la reparación integral del daño moral colectivo, independientemente de la posibilidad de mensuración individual de la ofensa o de la existencia de prueba de que hubo dolor, sentimiento o lesión psíquica a los individuos.

\section{REFERENCIAS}

Alsina, J. B. (1997). Teoría general de la responsabilidad civil. Buenos Aires: Abeledo-Perrot.

Amaro, E. A. (2009). Responsabilidade civil por ofensa aos derechos da personalidad. En: R. M. A Nery, y R. Donnini (Eds.), Responsabilidade civil: estudos em homenagem ao professor Rui Geral do Camargo Viana (pp. 157-171). Sao Paulo: RT.

Apraéz, B. E. (2015). La responsabilidad por producto defectuoso en la Ley 1480 de 2011. Explicación a partir de una obligación de seguridad de origen legal y constitucional. Revista de Derecho Privado, (28), 367-399.

Barbosa, F. N. y Multedo, R. V. (2014). Danos extrapatrimoniais coletivos. Revista de Derecho do Consumidor, 23(93), 29-45.

Beck, U. (1998). La sociedad del riesgo. Barcelona: Paidós Ibérica.

Beck, U. (2002). La sociedad del riesgo global. Madrid: Siglo Veintiuno de España.

Beck, U. (1997). A reinvenção da política: rumo a uma teoria a modernização reflexiva. En U. Beck, A. Giddens y S. Lash (Eds.), Modernização reflexiva: política, tradição e estética na ordem social moderna (11-71). Sao Paulo: Unesp.

Benjamin, A. H. V., Marques, C. L. y Bessa, L. R. (2007). Manual de derecho del consumidor. Sao Paulo: Revista dos Tribunais.

Borges, R. B. (2009). Derechos de personalidad e autonomia privada. Sao Paulo: Saraiva.

Brasil. Tribunal Superior de Justicia. (1992). Súmula 37. Corte Especial.

Brasil. Tribunal Superior de Justicia. (2011). Súmula 227. Relator: Ministro Ruy Rosado de Aguiar. Recuperado de https://ww2.stj.jus.br/docs_internet/revista/eletronica/stj-revista-sumulas-2011_17 capSumula227.pdf

Brasil. Tribunal Superior de Justicia. (2001). Recurso Especial 26975/RS. Relator: Ministro Aldir Passarinho Junior. Recuperado de https://stj.jusbrasil.com.br/jurisprudencia/291412/recursoespecial-resp-26975-rs-1992-0022571-3/inteiro-teor-10021686

Brasil. Tribunal Superior de Justicia (2006). Recurso Especial 598281/MG. Relator: Luiz Fux.

Brasil. Tribunal Superior de Justicia. (2009). Recurso Especial 1057274/RS. Relator: Ministra Eliana Calmon. Recuperado de https://stj.jusbrasil.com.br/jurisprudencia/19165433/recurso-especialresp-1057274-rs-2008-0104498-1/inteiro-teor-19165434?ref=juris-tab 
Brasil. Tribunal Superior de Justicia. (2012). Recurso Especial 1.221.756-RJ. Ministro Massami Uyeda. Recuperado de https://stj.jusbrasil.com.br/jurisprudencia/21222481/recurso-especial-resp1221756-rj-2010-0197076-6-stj/inteiro-teor-21222482

Brasil. Tribunal Superior de Justicia. (2018). Recurso Especial 1.397.870-MG. Relator: Ministra Assusete Magalhães. Recuperado de https://stj.jusbrasil.com.br/jurisprudencia/595783582/recurso-especialresp-1338955-mg-2012-0171787-7

Brasil. Congreso Nacional. (1990). Ley 8078 de septiembre 11 que dispone sobre la protección del consumidor y dicta otras providencias. Recuperado de http://derechodelturismo.net/ver/129/ ley-8078-de-defensa-del-consumidor

Cavalieri Filho, S. (2012). Programa de responsabilidade civil. Sao Paulo: Atlas.

Colombia. Congreso de la República. (2011). Ley 1480 de octubre 21 por medio de la cual se expide el estatuto del consumidor y se dictan otras disposiciones. Diario Oficial 48.220 de octubre 12 de 2011.

Cuéllar, J. C. (2014). La responsabilidad por producto defectuoso en el derecho colombiano. Revista Civilizar, (14), 17-39.

Farias, C. C. y Rosenvald, N. (2016). Curso de Derecho Civil: parte geral e LINDB. Salvador: Juspodium.

Galdós, J. M. (2009). El daño moral colectivo: su problemática actual. En R.L. Lorenzetti (Ed.), Derecho ambiental y daño (pp. 253-314). Buenos Aires: La Ley.

Mello, F. P. B. (2014). O dano não patrimonial transindividual. Revista de Derecho do Consumidor, 23(96), 41-74.

Mirra, A. L. V. (2010). Responsabilidade civil pelo dano ambiental e o princípio da reparação integral do dano. En N. Nery Júnior y R.M.A. Nery (Eds.), Responsabilidade Civil: doutrinas essenciais (pp. 435452). Sao Paulo: Editora Revista dos Tribunales.

Moraes, M. C. B. (2006). A constitucionalização do direito civil e seus efeitos sobre a responsabilidade civil. Revista Direito, Estado e Sociedade, 9(29), 233-258.

Mulholland, C. S. (2009) La responsabilidad civil por presunción de causalidad. Río de Janeiro: GZ.

Paccagnella, L. H. (2010). Dano moral ambiental. En N. Nery Júnior y R.M.A. Nery (Eds.), Responsabilidade Civil: doutrinas essenciais (pp. 591-602). Sao Paulo: Editora Revista dos Tribunales.

Santana, H. V. (2014). Dano moral no derecho do consumidor. Sao Paulo: RT.

Steigleder, A. M. (2004). Responsabilidade civil ambiental: as dimensões do dano ambiental no direito brasileiro. Porto Alegre: Livraria do Advogado. 